\title{
Does Time Difference in CT Scan Causes More Mortality?
}

\author{
Affirul Chairil Ariffin $^{1}$ (I) Hanizah Ngadiron ${ }^{2}$
}

Published online: 6 September 2017

(C) Société Internationale de Chirurgie 2017

We read with great interest the article by McKechnie et al. [1] discussing the role of computerised tomography (CT) in trauma. The article explains the differences in time for CT between trauma centres and non-trauma centres in Scotland. This issue is a common problem in the majority of hospitals worldwide. An organised trauma system has proven to be beneficial in reducing the time for CT scan significantly [2]. The data presented are consistent with materials available in the literature $[2,3]$.

CT scan proves to be an indispensable component in the evaluation of trauma patients, especially in haemodynamically stable patients [4]. Contrast-enhanced CT scan can detect liver and spleen lacerations, haematoma and active bleeding with a sensitivity up to $95 \%$ [5]. Hence, a difference of 9 min is significant, especially in abdominal injuries. Early diagnosis is imperative for an early intervention leading to a better outcome. Nonetheless, there are few issues which we believe will enhance the discussion further.

The analysis did not include the implication of such differences in both centres. It is important to evaluate the outcome and conclude whether the delay in imaging has any influence on the morbidity and mortality. Without this evidence, the necessity of time improvement within nontrauma centres remains contentious. Besides that, causes of CT delay should not be overlooked. By understanding

Affirul Chairil Ariffin

mraffirul@gmail.com

1 Surgery Department, Medical Faculty, Universiti Sains Islam Malaysia, Tingkat 13, Persiaran MPAJ, Jalan Pandan Utama, 55100 Kuala Lumpur, Malaysia

2 Emergency and Trauma Department, Universiti Sains Islam Malaysia, Jalan Pandan Utama, 55100 Kuala Lumpur, Malaysia these factors, efforts can be put to improve the trauma management in non-trauma centres. It is intriguing whether a proper analysis of these factors can be performed on a large data such as this.

Again, being a retrospective nature, it is a challenging task to obtain the appropriate data from a large multicenter national database. However, we do believe it is worthwhile considering the effect these findings might have towards the trauma care especially in non-trauma centres.

\section{References}

1. McKechnie PS, Kerslake DA, Parks RW (2017) Time to CT and surgery for HPB trauma in Scotland prior to the introduction of major trauma centres. World J Surg. 41:1796-1800. doi:10.1007/ s00268-017-3934-6

2. Fung Kon Jin PH, van Geene AR, Linnau KF et al (2009) Time factors associated with $\mathrm{CT}$ scan usage in trauma patients. Eur $\mathrm{J}$ Radiol 72:134-138

3. Dambrauskas Z, Aukstakalnis V, Karbonskiene A et al (2017) How the changes in the system affect trauma care provision: The assessment of and implications for Lithuanian trauma service performance in 2007-2012. Medicina (Kaunas) 53:50-57

4. Cline Michael R, Cherry-Bukoweiz Jill, Machado-Aranda David et al (2016) Diagnostic limits, blind spots, and pitfalls in CT imaging of blunt abdominal trauma. Contemp Diagn Radiol $39: 1-6$

5. Vela JH, Wertz CI, Onstott KL, Wertz JR (2017) Trauma imaging: a literature review. Radiol Technol 88:263-276 